\title{
LOS IMPACTOS DE LA PANDEMIA DE LA COVID-19 EN LOS \\ MERCADOS LABORALES DE AMÉRICA LATINA
}

\section{THE IMPACTS OF THE COVID-19 PANDEMIC ON THE \\ LABOR MARKETS OF LATIN AMERICA}

\author{
Jacobo Velasco ${ }^{1}$
}

\begin{abstract}
Palabras clave: Resumen
La pandemia de la COVID-19 tuvo efecto sin precedentes en los

Mercados

laborales,

América Latina, mercados laborales de América Latina, tanto en los niveles de caída de la oferta y demanda laboral, como por el cambio en la dinámica COVID-19 de ajuste. Este análisis pone en contexto los efectos de la pandemia en comparación con crisis precedentes y además aporta una visión general de las respuestas de política sociolaboral.
\end{abstract}

Códigos JEL: R23, E24, F16

\section{Keywords: \\ Labor markets, Latin America, COVID-19}

\begin{abstract}
The COVID-19 pandemic had an unprecedented effect on Latin American labor markets, both in terms of the drop in labor supply and demand, as well as the change in the adjustment dynamics. This analysis puts in context the effects of the pandemic in comparison with previous crises and also provides an overview of socio-labor policy responses.
\end{abstract}

\footnotetext{
${ }^{1}$ Organización Internacional del Trabajo (OIT) oficina de Santiago de Chile Email: velascoj@ilo.org
} 


\section{INTRODUCCIÓN}

La pandemia del COVID-19 generó en 2020 la mayor crisis económica que América Latina y el Caribe habrá experimentado en su historia, con una contracción estimada del PIB regional de $9,1 \%$. La fuerte contracción económica ha tenido un impacto significativo en el mercado laboral de la región, con consecuencias en la destrucción de empleos, en el aumento de la desocupación y en la precarización de las condiciones laborales. Si bien la región ha enfrentado diversas crisis que impactaron sus economías y mercados laborales, generando grandes desafíos para las políticas sociolaborales, ninguna tuvo la rapidez, profundidad e impacto en la demanda y oferta de las economías y en los mercados laborales de la región como la crisis sanitaria. A su vez, históricamente las crisis gatillaron presiones en los marcos institucionales y en la capacidad para la articulación de las políticas sociolaborales, lo que ha implicado revisar y generar arreglos en la arquitectura institucional y en los instrumentos para la toma de decisiones. A la hora de generar una respuesta a la crisis frente a la pandemia de la COVID-19, estos desafíos también se presentan a una escala global, regional y nacional.

La respuesta inmediata a la pandemia ha implicado medidas de contención que afectan tanto la oferta y la demanda económica y laboral, con incertidumbre sobre el proceso de normalización y sobre la efectividad de las políticas para acompañar dicho proceso. La necesidad de enfrentar los efectos crisis de la COVID-19 en los países de América Latina y el Caribe ofrece una oportunidad para reflexionar sobre el tipo de respuestas a la crisis cuando requieren complementariedad de políticas (salud, económicas, laborales y de seguridad social) y de plazos, que afecta de forma distinta (sectores, tamaños de empresa, grupos vulnerables) a la oferta y demanda laboral, y a la capacidad de las instituciones sociolaborales para dar una respuesta oportuna. Como consecuencia toma importancia revisitar las experiencias de respuestas a crisis, el tipo de políticas disponibles y los requerimientos de nuevas políticas y articulaciones institucionales para enfrentar los efectos de corto y mediano plazo de la pandemia de la COVID-19.

\section{¿En qué se distingue la crisis de la COVID-19 de otras crisis?}

\subsection{Causa, velocidad y profundidad distinta}

Los efectos de la pandemia de la COVID19 no tienen precedentes en la historia de América Latina y el Caribe en conjunto. Si bien se intenta establecer paralelos con crisis precedentes (financiera de 20082009, Gran Depresión de los años 30, crisis de la deuda en los años 80), que afectaron las economías y mercados laborales de la región, estas crisis tuvieron un origen en el sector financiero, fiscal o productivo con canales de transmisión (comercio, tasas de interés, términos de intercambio) que afectaron a otros sectores y a las economías en su agregado. Las crisis anteriores han impactado al mercado laboral, por la vía del aumento de la desocupación y del empleo informal, así como por la precarización de las condiciones laborales (Ocampo, 2011). Más aún, si bien las crisis han generado pérdidas de empleos, los incrementos de la desocupación fueron atenuados por los trasvasijes desde la formalidad de los empleos perdidos hacia la informalidad. Por ende, históricamente el sector informal se convirtió en un gran colchón que absorbió la pérdida de puestos de trabajo, aunque con condiciones de empleo e 
ingresos más precarios (OIT, 2014; CEPAL-OIT, 2014). En particular, los recurrentes ciclos recesivos de los ochenta y noventa implicaron que la recuperación del empleo era liderada por el sector

informal, lo que significaba precarización de las condiciones laborales y dificultad para el retorno de los nuevos informales al sector formal por el llamado efecto "cicatriz", por la mala señal que el trabajo informal de baja productividad representa para los empleadores formales (SalazarXirinachs y Chacaltana, 2018).

La crisis producto de la COVID-19 es muy particular porque es de carácter internacional, originada por un virus de alta transmisibilidad, que ante la ausencia de una vacuna o tratamiento generó medidas sanitarias de aislamiento, la extensión de cuarentenas totales o parciales, y la interrupción de la actividad económica no esencial y de las cadenas globales de suministro (Baldwin y Di Mauro, 2020; Banco Mundial, 2020). Estas medidas y efectos se tornaron globales en pocas semanas, con una generalización de las medidas sanitarias y de contención del virus desde marzo, impactando a la baja tanto los precios de bienes y servicios, como los volúmenes de comercio de los mismos ${ }^{2}$ (Banco Mundial, 2020; CEPAL, 2020a).

La rapidez de estos efectos en la oferta y demanda de las economías provocaron cambios significativos en las estimaciones de crecimiento y de su impacto en el empleo (Gráfico 1). Luego de un año 2019 donde la economía global $(2,4 \%)$ y regional $(0,1 \%)$ crecieron bajo el promedio de 2015-2018 (CEPAL, 2019a), las expectativas para 2020, que apuntaban a desempeños más robustos, se ajustaron sensiblemente a la baja producto de la crisis sanitaria. Así, para abril, la estimación del crecimiento del PIB global $(-2,0 \%)$ y regional $(-5,3 \%)$ daba cuenta del impacto significativo que las medidas de contención de la pandemia tenían sobre el sistema económico planetario y latinoamericano (CEPAL, 2020a). Esta dinámica tiene implicaciones directas sobre el empleo que causarían una reducción de las horas de trabajo de alrededor de $-6,7 \%$ a nivel global y $-5,7 \%$ a nivel regional, el equivalente a 195 millones y 14 millones de trabajadores a tiempo completo (suponiendo un tiempo de trabajo de 48 horas semanales), respectivamente (OIT, 2020a ${ }^{3}$ ).

\footnotetext{
2 La Organización Mundial del Comercio (OMC) estima que el comercio mundial caerá entre un $13 \%$ y un $32 \%$ en 2020 . Además se estima que los precios y volumen de exportaciones de América Latina y el Caribe se reducirán en 2020 en $6 \%$ y 8,8\%, respectivamente (CEPAL, 2020a).
}

\footnotetext{
3 Complementado con información de América Latina y el Caribe con informe de prensa: https://www.ilo.org/americas/sala-deprensa/WCMS 741222/lang--es/index.htm
} 


\section{Gráfico 1.}

Crecimiento económico global y regional en 2019-2020 y posibles impactos en número de horas trabajadas en 2020 (en tasas de crecimiento)

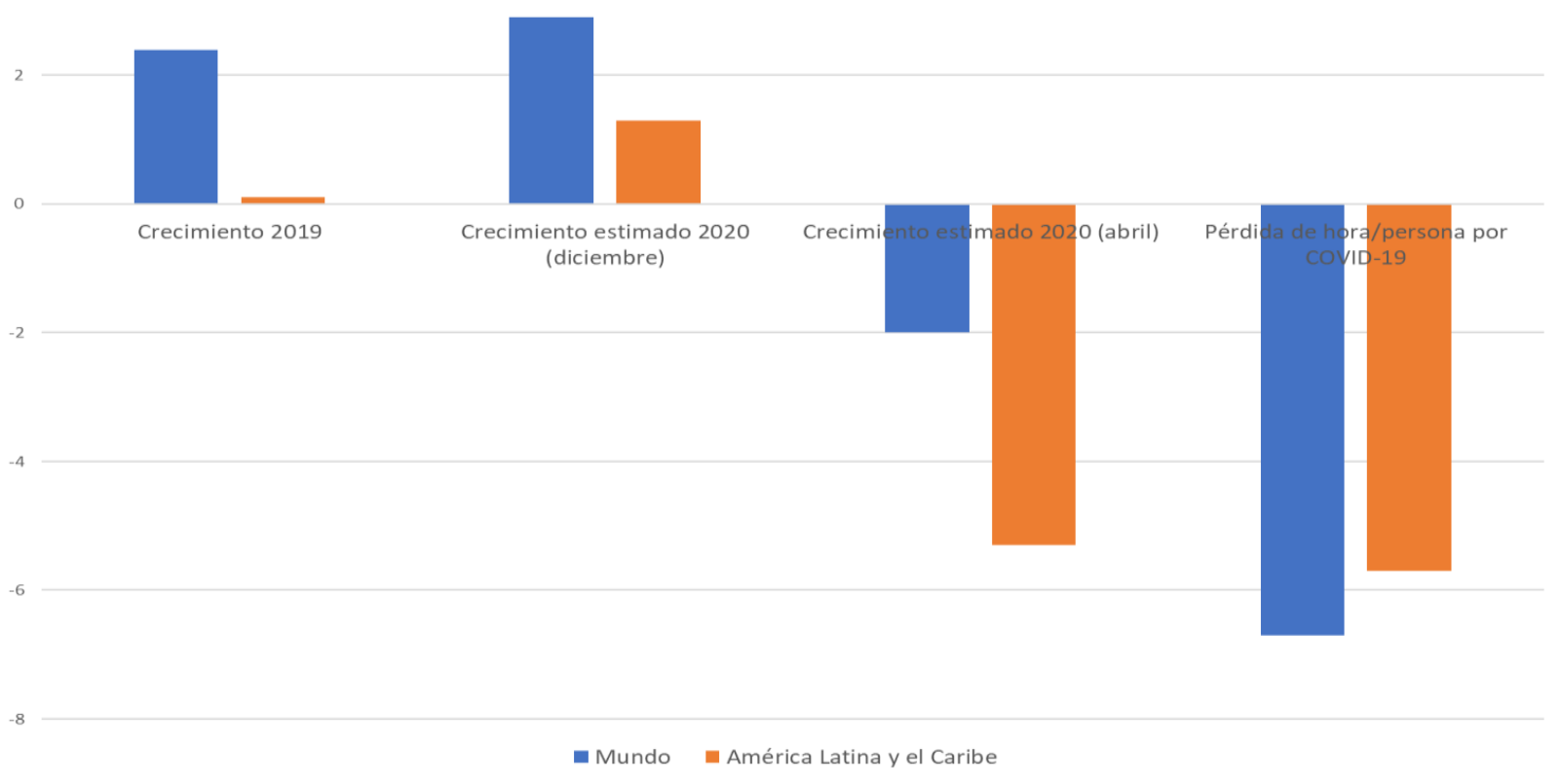

Fuente: Comisión Económica para América Latina y el Caribe (CEPAL) y Organización Internacional del Trabajo (OIT), sobre la base de CEPAL (2019a, 2020a) y OIT (2020a).

La expansión veloz de la pandemia y de las medidas para controlarla también tuvo efectos sectoriales y estructurales a nivel económico y laboral. En particular, se estima que el impacto en la actividad económica y el empleo como consecuencia de la COVID-19 fue alto en sectores como Comercio; Industrias manufactureras; Actividades de alojamiento y de servicio de comidas (asociadas al turismo); y Actividades inmobiliarias, mientras que en sectores como Transporte y almacenamiento; y Artes, entretenimiento y recreación, el impacto será medio-alto
(OIT, 2020a). Como se observa en el Gráfico 2, los sectores de alto impacto concentran alrededor de 4 de cada 10 trabajadores a nivel mundial y regional. En esos sectores también se observa una proporción importante de participación de las mujeres, superando el $40 \%$ global y regionalmente. Por otra parte, la pandemia se presenta en mercados laborales en que cerca de la mitad de los trabajadores no agrícolas son informales (OIT, 2018a), y en un contexto en que la población mundial $(45 \%)$ y regional $(61 \%)$ cuenta con al menos una prestación de protección social (OIT, 2017). 


\section{Gráfico 2.}

\section{Estimaciones globales y regionales del empleo en sectores en situación de riesgo, informalidad y cobertura de protección social. (en porcentajes)}

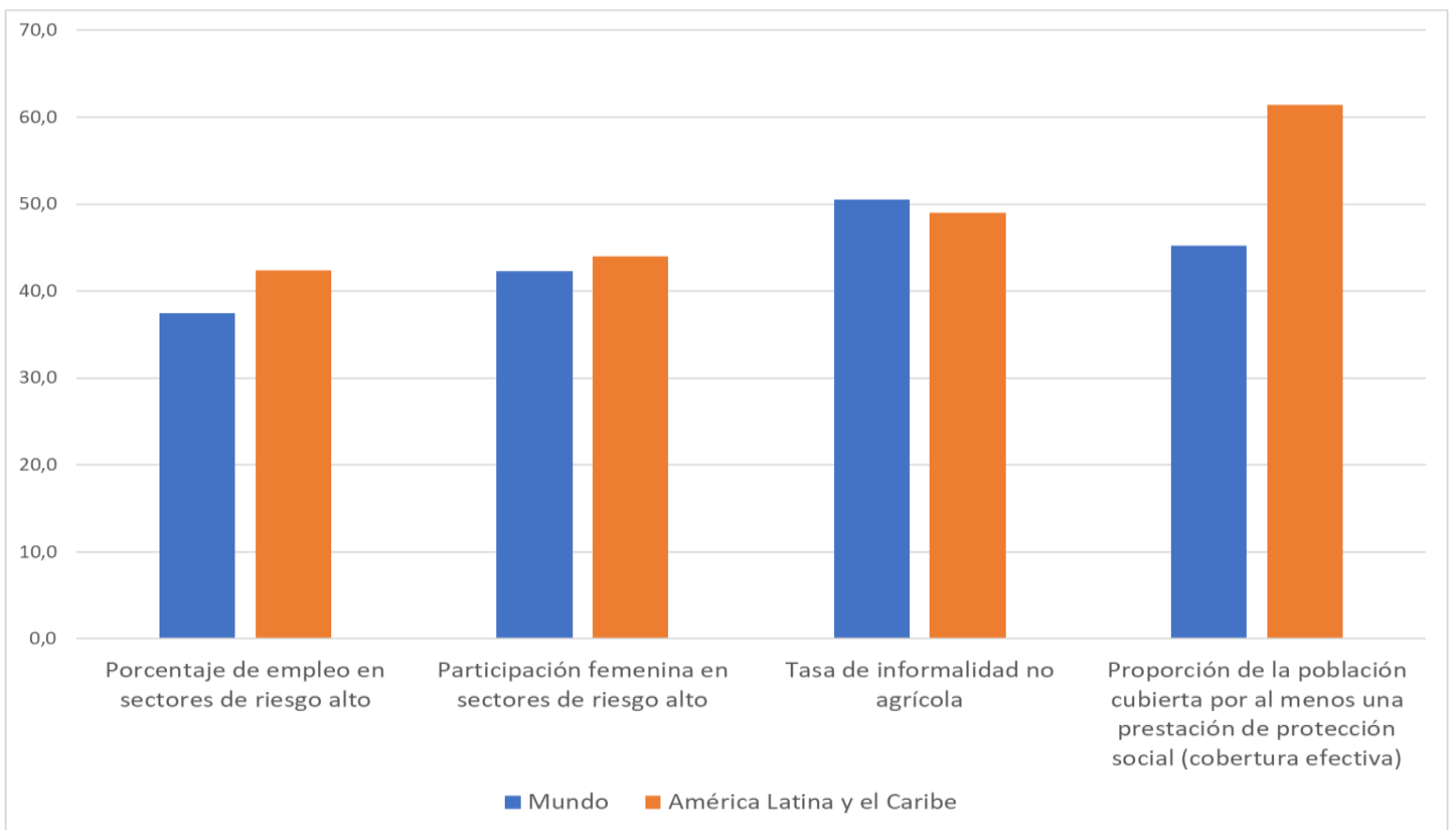

Fuente: Comisión Económica para América Latina y el Caribe (CEPAL) y Organización Internacional del Trabajo (OIT), sobre la base de OIT (2020a, 2018a y 2017)

Para enfrentar esta situación, a nivel internacional los países reforzaron los sistemas sanitarios, así como también se adoptaron políticas monetarias y fiscales expansivas de carácter anticíclico. En materia laboral, protegió la relación de trabajo y la viabilidad de las empresas, así como de dar ingresos a los trabajadores independientes e informales para que puedan transitar por esta coyuntura. En particular, la evidencia internacional muestra que los países han adoptado políticas de acción en torno a tres áreas: la protección de los trabajadores en el lugar de trabajo, el fomento de la actividad económica y de la demanda de mano de obra, y el apoyo al empleo y al mantenimiento de los ingresos (OIT, 2020b). En cuanto a la protección de los trabajadores en el lugar de trabajo, destacan medidas como el trabajo a distancia y el establecimiento de turnos de trabajo, la ampliación del derecho a bajas por enfermedad remuneradas a trabajadores que no se encuentran bien o están en cuarentena, asesoramiento en materia de Seguridad y Salud en el Trabajo (SST) vía atención telefónica, sitios web específicos y difusión de información, y la prestación de servicios de cuidado infantil para los padres que trabajan en varios países en los que se han cerrado escuelas y guarderías. Por otra parte, en el marco de las políticas de fomento a la actividad económica y de la demanda de mano de obra destacan la reducción de tasas de interés por parte de los Bancos Centrales, estímulos fiscales (exenciones o postergaciones tributarias, incrementos de gasto público en salud y/o protección social) y la prestación de apoyo financiero a sectores específicos. Finalmente, las políticas de apoyo al empleo y al mantenimiento de los ingresos incluyen acuerdos sobre reducción del horario de trabajo y en materia de compensación, la promoción de la conservación del empleo por la vía de préstamos asociados al mantenimiento de los puestos de trabajo y salarios, la ampliación de las prestaciones por 
desempleo para trabajadores formales y de las prestaciones de asistencia social con especial foco en trabajadores informales y sus familias.

\subsection{Desafíos para las respuestas de políticas a la COVID-19 en América Latina y el Caribe}

Como se mencionó, la expansión de la COVID-19 en América Latina y el Caribe ha sido rápida, lo mismo que la aplicación de medidas de contingencia frente a la pandemia ${ }^{4}$. En ese sentido, la secuencia de los efectos de estas medidas en la oferta y demanda productiva y en los mercados laborales, tuvo un impacto a nivel regional tanto en la fuerte contracción del PIB (en torno al $-7,0 \%$ ) como en la pérdida de puestos de trabajo y el aumento de la tasa de desocupación, estimado en 2,1 puntos porcentuales para este año (CEPAL-OIT, 2021). Comparativamente, la contracción económica de 2020 es mucho más profunda que la observada en $2009(-1,8 \%)$ que fue de nivel similar al impacto de la crisis de la deuda de 1982 (Ocampo, 2011). No obstante, a diferencia de lo observado en los ochentas, la tasa de desocupación regional y los indicadores sociolaborales volvieron a su nivel pre-crisis en 2010 en la mayoría de países producto de la rápida recuperación de la dinámica económica global y a una respuesta activa de políticas sociolaborales (OIT, 2011; CEPAL, 2011; Marinakis, 2011). A esta respuesta favorecieron capacidades fiscales para articular políticas

\footnotetext{
4 De acuerdo al Oxford COVID-19 Goverment Response Tracker mientras que a fines de febrero se habían registrado casos en Brasil y México, para el 15 de marzo 28 países reportaron eventos, lo que se extendió a 37 países de la región el 1 de abril. A su vez, las medidas de restricción interna fueron aumentando. Mientras hasta el 15 de marzo había recomendaciones de distanciamiento social en 6 países, para el 1 de abril 29 países registraban medidas locales o nacionales de confinamiento.

5 En el período 2003-2008, 15 de los 19 países latinoamericanos tuvieron un superávit primario,
}

contracíclicas con mayor holgura respecto de otras crisis regionales ${ }^{5}$. Así, junto con la construcción progresiva de instrumentos de política laboral y de protección social precrisis, se generaron espacios para implementar nuevas políticas durante la crisis de 2009 (Marinakis y Velásquez, 2010; CEPAL-OIT, 2011; OIT, 2010; CEPAL, 2010; Marinakis, 2011). También se aprecian avances institucionales y de política post crisis-2009, en particular con la formalización del empleo y del tejido productivo (Salazar -Xirinachs y Chacaltana, 2018; OIT, 2014), la mejora de las fuentes de información estadística (Dargent et al., 2018; Gontero y Zambrano, 2018), y el aumento de los programas de empleo $^{6}$ y protección social (OIT, 2016; Mourelo, 2018; OIT, 2018b). Pese a ello, se aprecia que el gasto público en políticas de empleo (menor al 1\% del PIB) es bajo en comparación a la media de los países de la OECD, y que dicho gasto necesita mejorar su impacto (Escudero et al., 2017; Mourelo, 2018; CEPAL, 2019).

Junto con los antecedentes de la respuesta a la crisis de 2009 y algunos avances en la arquitectura de las políticas sociolaborales, existen otros elementos que influyen en la dirección y capacidad de respuesta regional a la crisis del COVID-19. Como se aprecia en el Cuadro 1, si bien se han dado avances en la reducción de la informalidad, en los últimos años se aprecian elementos tendenciales (mayor crecimiento del empleo por cuenta propia y de la subocupación, ralentización del empleo registrado) que sugieren que ese proceso se

mientras que el resultado global (teniendo en cuenta los pagos de la deuda pública) estuvo cerca del equilibrio del promedio del país en los mismos años (CEPAL, 2010).

6 Los programas de empleo (capacitación, servicios de trabajo, incentivos al sector privado, empleos públicos) en la región aumentaron progresivamente desde niveles mínimos en los noventas hasta ser mucho más extendidos, particularmente en la década de 2010 (Escudero et al., 2017; Mourelo, 2018) 
estaría revirtiendo en varios países. La recesión de 2020 aumentaría la informalidad tanto por la pérdida de empleos formales que pasen a la informalidad como por la suspensión temporal de la relación laboral que implique, en la práctica, empleos sin acceso a beneficios laborales ni protección social. Ello complejizaría los objetivos de política de empleo como de protección social y la capacidad para dar respuesta coordinada. Por otra parte, la región ha seguido un proceso constante de concentración del empleo en los sectores de servicios, que son los que más crecen y empleos generan (ver sección 1): 7 de cada 10 trabajadores están en el sector terciario y 1 de 4 trabajan en Comercio (OIT, 2020c). Dado que el impacto de las políticas de contención del COVID-19 en los sectores de servicios será alto o medio-alto, y que en estos sectores se observa mayor informalidad, las respuestas de política requieren focalización en el sostenimiento del empleo y de sus condiciones en estos sectores. Ello es particularmente medular en países como los del Caribe, con una concentración relativa mayor en servicios, sobre todo asociados al turismo.

La región también ha experimentado un crecimiento de la participación y ocupación femenina que se concentra en los sectores de servicios (CEPAL-OIT, 2019a; OIT, 2019). Además, las mujeres de la región trabajan en condiciones de informalidad $(51,8 \%)$ mayores que los hombres $(46,8 \%)$ (OIT, 2018). Por ende, las respuestas de política sociolaboral deben incluir una dimensión de género. Otra tendencia está vinculada con el aumento de la migración intrarregional, impulsada por la migración venezolana desde 2014 (CEPAL-OIT, 2017). Ello supone un escenario diferente respecto de otras crisis para muchos países receptores de migración tanto por la concentración del empleo migrante en servicios como por el desafío de integrar a los trabajadores migrantes formales $\mathrm{e}$ informales en las respuestas de política.
También se aprecia a nivel regional un aumento progresivo del trabajo por plataformas digitales, que genera desafíos importantes tanto para la regulación como para la implementación de políticas de empleo y protección social (CEPAL-OIT, 2019b). Paralelamente, si bien el teletrabajo se observa como una alternativa durante el confinamiento, sobre todo para los trabajadores formales en áreas administrativas y sectores no manuales, tiene complejidades asociadas a la relativa ausencia de regulación pre-COVID como de instrumentos que aseguren su cumplimiento.

Por otra parte, si bien se han ampliado las políticas de empleo, los progresos se observan insuficientes en un contexto más general. Por ejemplo, en 2019 solo en Argentina, Brasil, Chile, Colombia, Ecuador y Uruguay, los trabajadores del sector formal tenían seguro de desempleo (CEPAL, 2020b). Estos espacios para avanzar son particularmente notorios en las políticas de SST en una crisis como la del COVID-19, en que el set de políticas laborales contracíclicas necesariamente requiere elevar a un rol más protagónico a las políticas de SST. A su vez, para articular una respuesta fiscal contracíclica frente al COVID-10, la generalidad de los países de América Latina y el Caribe se encuentra con poco espacio para aumentar su gasto fiscal por el mayor endeudamiento, el creciente pago de intereses, ingresos fiscales más limitados y las restricciones propias de las restricciones para buscar emitir deuda en un contexto financiero internacional restrictivo (CEPAL, 2020a). No obstante, el contexto regional de inflación baja y controlada (CEPAL, 2019b), abrió márgenes para respuestas de política monetaria y crediticias expansivas. A su vez, junto con una tendencia reciente de salarios mínimos más moderados, la activación de esta política tendría limitaciones en un contexto como el del COVID-19, en que las empresas, particularmente las MYPIMES, ven 
afectadas su capacidad de pago por la disminución de actividad. Finalmente, las medidas de confinamiento suponen complicaciones para el normal desarrollo de las encuestas de empleo en la región, lo que dificultó el monitoreo del impacto de las políticas en el mercado laboral (CEPAL-OIT, 2020a). Por ende, se implementaron medidas contingentes (encuestas telefónicas), para complementar información con otras fuentes de información (ver Tabla 1).

Tabla 1.

América Latina y el Caribe, principales desafíos de política frente a la coyuntura del COVID-19.

\begin{tabular}{|c|c|}
\hline $\begin{array}{l}\text { Tendencias anteriores y } \\
\text { cambios por COVID }\end{array}$ & Desafíos de políticas \\
\hline $\begin{array}{l}\text { Posibilidad de regresión en la } \\
\text { informalidad }\end{array}$ & $\begin{array}{l}\text { Coordinación de políticas de empleo y protección } \\
\text { social }\end{array}$ \\
\hline $\begin{array}{l}\text { Aumento del empleo en los } \\
\text { sectores de servicios }\end{array}$ & $\begin{array}{l}\text { Impacto significativo en sectores cruciales para } \\
\text { algunos países (turismo) }\end{array}$ \\
\hline Aumento del empleo femenino & Incluir dimensión de género \\
\hline Menor espacio fiscal & Dificultad para implementar políticas contracíclicas \\
\hline Inflación baja & Posibilidad para políticas monetarias \\
\hline Rol secundario de la SST & $\begin{array}{c}\text { Necesidad de avanzar en rol y promoción de las } \\
\text { políticas de SST }\end{array}$ \\
\hline $\begin{array}{l}\text { Extensión del trabajo por } \\
\text { plataformas }\end{array}$ & $\begin{array}{l}\text { Límites para aplicar políticas que beneficien a } \\
\text { trabajadores }\end{array}$ \\
\hline $\begin{array}{l}\text { Pese a avances, políticas de } \\
\text { empleo no tan extendidas }\end{array}$ & $\begin{array}{l}\text { Necesidad para incorporar políticas de empleo o } \\
\text { extenderlas }\end{array}$ \\
\hline Incremento de la migración & Incorporar a los migrantes en las respuestas \\
\hline Teletrabajo & Limitada legislación \\
\hline $\begin{array}{l}\text { Ralentización de los salarios } \\
\text { mínimos }\end{array}$ & Dificultad para usarlo como instrumento \\
\hline $\begin{array}{l}\text { Dificultad para realizar encuestas } \\
\text { de empleo }\end{array}$ & Necesidad de desarrollar sistema de información \\
\hline
\end{tabular}

El contexto, tendencias y antecedentes condicionaron las respuestas de política sociolaboral de los países de la región frente a la COVID-19. En particular, las buenas prácticas de políticas que se han implementado a nivel internacional han correspondido a muchos países con estructuras de mercado laboral más formales y con mayor espacio fiscal, aunque en términos generales, se observa que los países de la región implementaron líneas similares. En particular, destacan las acciones vinculadas con el uso de las políticas de transferencias e ingresos para trabajadores, empresas y personas fuera de la fuerza laboral que los gobiernos han 
implementado desde 2020 (CEPAL, 2020a, 2021; OIT, 2020, Velásquez, 2021). Entre estas se incluyen los seguros de desempleo, tanto en su implementación como en su reformulación como instrumentos que aseguren ingresos durante la suspensión temporal de actividades y, por otro lado, las transferencias de ingresos a los trabajadores informales y sus familias. Otras fórmulas implementadas han tenido que ver con los ajustes pactados tanto en el tiempo de trabajo como en la suspensión temporal de actividades, junto con subsidios, créditos y transferencias a empresas y personas. Así también se aprecia el uso de políticas que se implementaron para la regulación y adopción del teletrabajo, que se extendió regionalmente en 2020, así como de las políticas de SST, en particular aquellas vinculadas con el acondicionamiento de las instalaciones para el regreso presencial (CEPAL, 2021; OIT, 2020b). Si bien estas políticas fueron generales, se dieron dentro de las condicionantes propias del estrecho espacio fiscal que han tenido los países, lo que dificulta su sostenibilidad en el mediano plazo. A su vez, también se aprecia las dificultades para establecer políticas orientadas a grupos y sectores específicos. Ello se observa particularmente en a nivel de políticas con dimensiones particulares para mujeres y jóvenes, migrantes, trabajadoras domésticas remuneradas y sectores altamente impactados. A continuación, se discuten algunas de estas dimensiones con más detalle.

\section{Los impactos de la pandemia en el mercado laboral latinoamericano}

Los efectos de la pandemia han sido particularmente evidentes en el mercado laboral. Sin embargo, estos impactos han sido distintos respecto de otras crisis, tanto por el comportamiento de los principales indicadores del mercado laboral regional como por las respuestas de política observados en esta crisis. En esta sección se discuten estos aspectos.

\subsection{Fuertes impactos en el empleo y la participación}

Los efectos de las medidas de salud pública para contener la pandemia, tuvieron un impacto tanto en la economía como en el mercado laboral que fue profundizándose conforme las medidas de confinamiento tuvieron que prolongarse o, por otra parte, revertirse a través del desconfinamiento progresivo. Si bien los matices cambian dependiendo de la profundidad y duración de las medidas nacionales de contención a la pandemia, la región experimentó el doble efecto de la contracción de la oferta y demanda económica que a nivel laboral se tradujo en la fuerte disminución de la ocupación y de la participación laboral (Gráfico 3) como resultado de que la contracción económica experimentada en $2020(-7,0 \%)$ fue la más importante de la que se tenga registro (CEPAL, 2020c). Así, en 2020 la tasa de ocupación regional experimentó una caída de 5,5 puntos porcentuales, mientras que la tasa de participación se contrajo 4,5 puntos porcentuales. El efecto de la contracción más profunda de la ocupación respecto de la participación provocó un aumento de 2,1 puntos porcentuales de la tasa de desocupación regional, que superó los dos dígitos en 2020, por primera vez en más de una década. 


\section{Gráfico 3.}

América Latina y el Caribe: variación de las tasas de participación y ocupación y tasa de crecimiento económico, 2012-2020. (En puntos porcentuales y porcentajes)

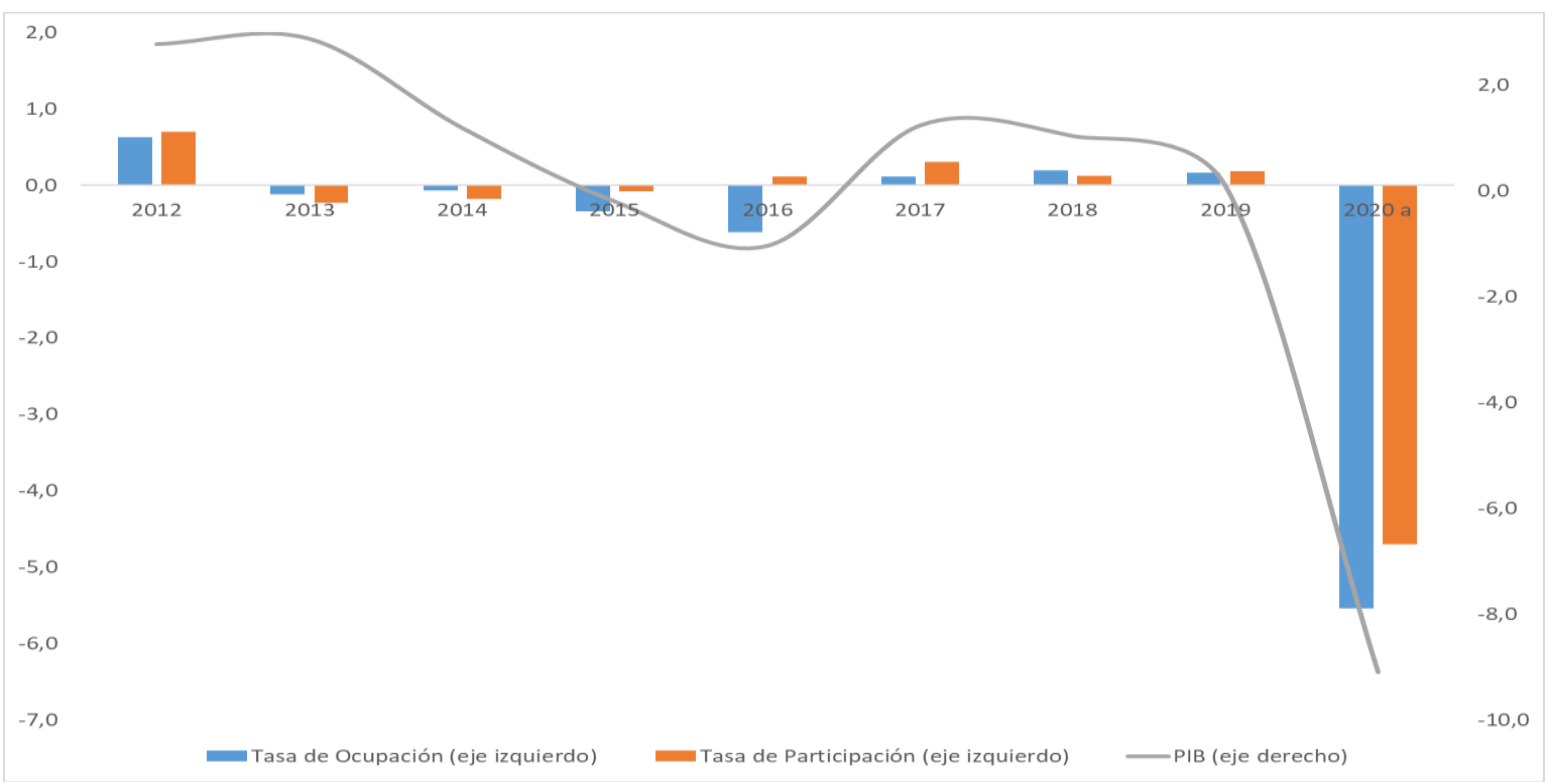

Fuente: Comisión Económica para América Latina y el Caribe (CEPAL) y Organización Internacional del Trabajo (OIT), sobre la base de información oficial de los países a Datos preliminares.

Por otra parte, la respuesta del mercado laboral regional durante 2020 reflejó claramente tanto los efectos de las medidas de confinamiento y contención de la pandemia, como su reversión paulatina. Como se puede apreciar en el Gráfico 4, si bien las tasas de participación y ocupación empezaron a reducirse en el primer trimestre de 2020, como consecuencia del inicio de las medidas de confinamiento en el mes de marzo, estos indicadores se contrajeron con mayor intensidad durante el segundo trimestre de 2020, cuando todos los países de la región implementaron medidas de confinamiento obligatorio. En el segundo trimestre de 2020, la reducción de la tasa de ocupación (-10,2 puntos porcentuales) fue más profunda que la de la tasa de participación $(-9,6$ puntos porcentuales), lo que inmediatamente se reflejó en el fuerte incremento de la tasa de desocupación (2,7 puntos porcentuales). $\mathrm{Si}$ bien, como resultado de la reversión paulatina de las medidas de confinamiento, en el tercer y cuarto trimestres la contracción de las tasas de participación y ocupación se han ido atenuando en términos interanuales, muestran comportamientos distintos a los del segundo trimestre: las tasas de ocupación y participación tienden a recuperarse en el segundo semestre respecto de las caídas registradas en el segundo trimestre. 


\section{Gráfico 4.}

América Latina y el Caribe (13 países) a: variación interanual de las tasas de participación, ocupación y desocupación, primer trimestre de 2017 a cuarto trimestre de $2020 b$. (En puntos porcentuales y porcentajes).

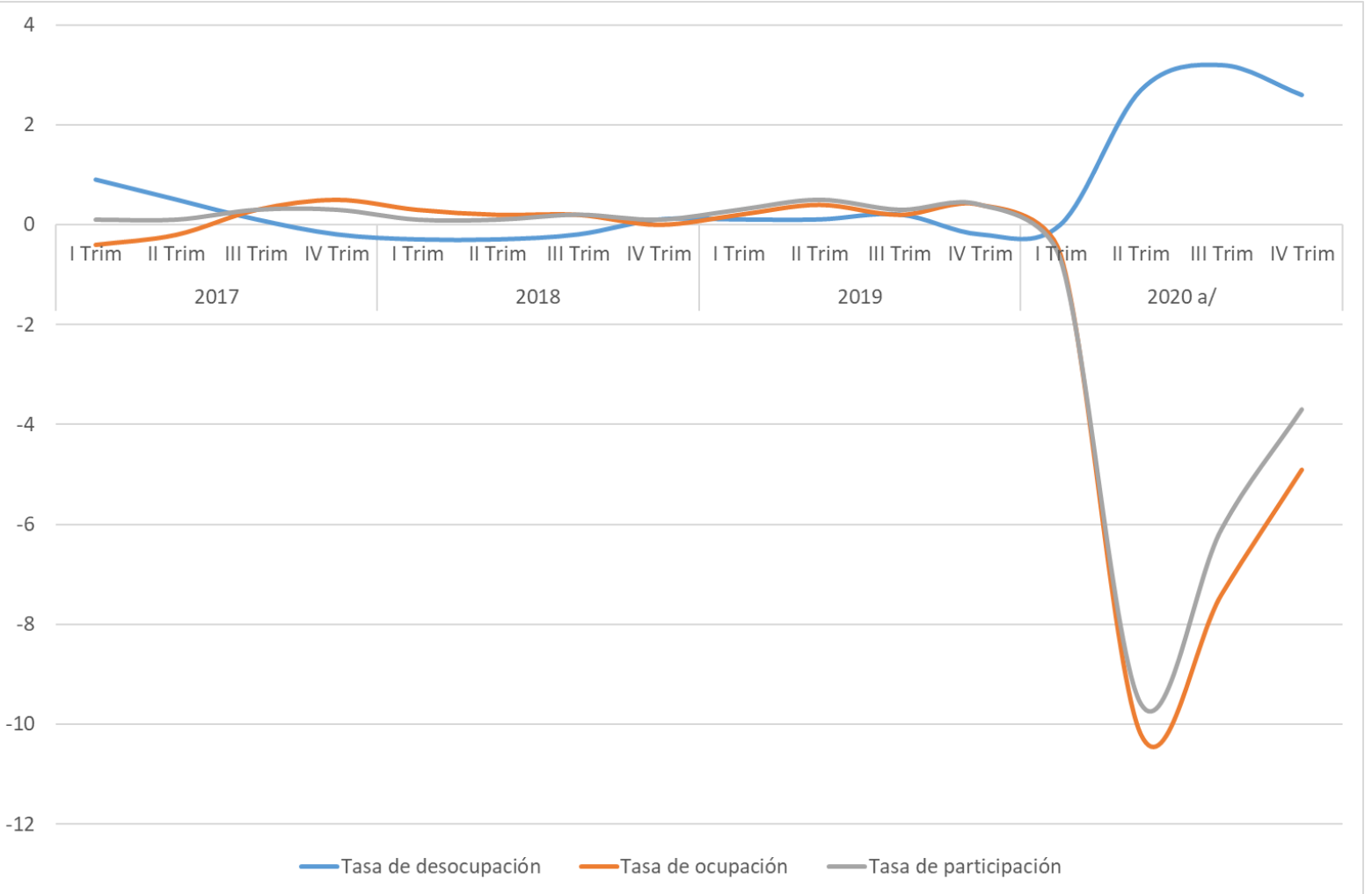

Fuente: Comisión Económica para América Latina y el Caribe (CEPAL) y Organización Internacional del Trabajo (OIT), sobre la base de información oficial de los países

a) Promedio ponderado de los siguientes países: Argentina, Bolivia, Brasil, Chile, Colombia, Costa Rica, Ecuador, Jamaica, México, Paraguay, Perú, República Dominicana y Uruguay. Se incluyen estimaciones basadas en datos parciales.

b) Los datos de 2020 son preliminares.

Por otra parte, también se observa que la crisis económica producto de la pandemia de la COVID-19 impactó negativamente a las tasas de participación y ocupación en 18 países con información disponible para 2020. En efecto, las tasas de ocupación y participación disminuyeron, con excepción de Honduras, en donde la tasa de participación aumentó. No obstante, la contracción de la tasa de ocupación fue más profunda que la caída de la tasa de participación en 16 países. Ello resultó en un aumento de las tasas de desocupación en ese grupo de países (Gráfico 5). Por el contrario, las tasas de participación se contrajeron más en Nicaragua y República Dominicana, lo que produjo un descenso de sus tasas de desocupación. 


\section{Gráfico 5.}

América Latina y el Caribe (18 países): variación interanual de la tasa de desocupación, por país, 2018-2019 y 2019-2020 (En puntos porcentuales).

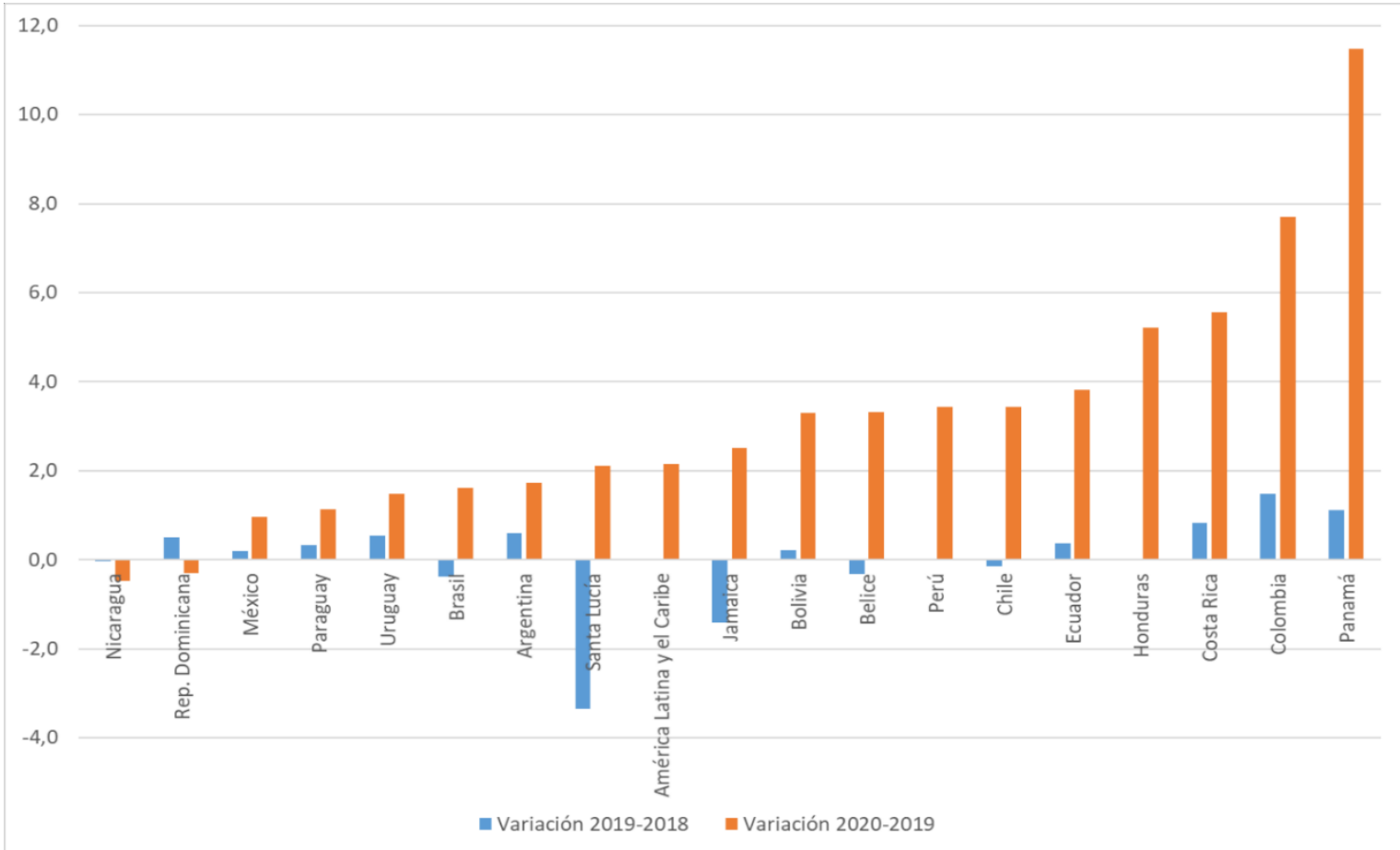

Fuente: Comisión Económica para América Latina y el Caribe (CEPAL) y Organización Internacional del Trabajo (OIT), sobre la base de información oficial de los países.

Por otra parte, el flujo de entrada de mujeres al mercado laboral ha explicado por qué en las crisis anteriores, la tasa de participación regional tuvo una reacción pro-cíclica más lenta, a contramano de lo que sí se observó en la tasa de ocupación en periodos de contracción económica (CEPAL-OIT, 2019; Panorama Laboral, 2019). La crisis sanitaria, en cambio, produjo una reducción regional generalizada de la tasa de participación femenina, lo que supone un gran retroceso respecto de los avances observados en la participación laboral de las mujeres. Como muestra el Gráfico I.6, en los 16 países con información disponible, exceptuando a Honduras, las tasas de participación femenina cayeron en 2020. En 7 de esos países, la magnitud de la contracción de la tasa de participación femenina de 2020 fue más significativa que los incrementos de la tasa de participación entre 2019 y 2012, destacándose en particular los retrocesos observados en Belice y Chile. A su vez, las contracciones de la tasa de participación femenina de 2020 exacerbaron las caídas observadas entre 2019 y 2012 en Perú, Costa Rica y Nicaragua. 


\section{Gráfico 6.}

América Latina y el Caribe (16 países): variación de las tasas de participación femenina a nivel nacional, periodo 2019-2012 y 2020-2019. (En puntos porcentuales).

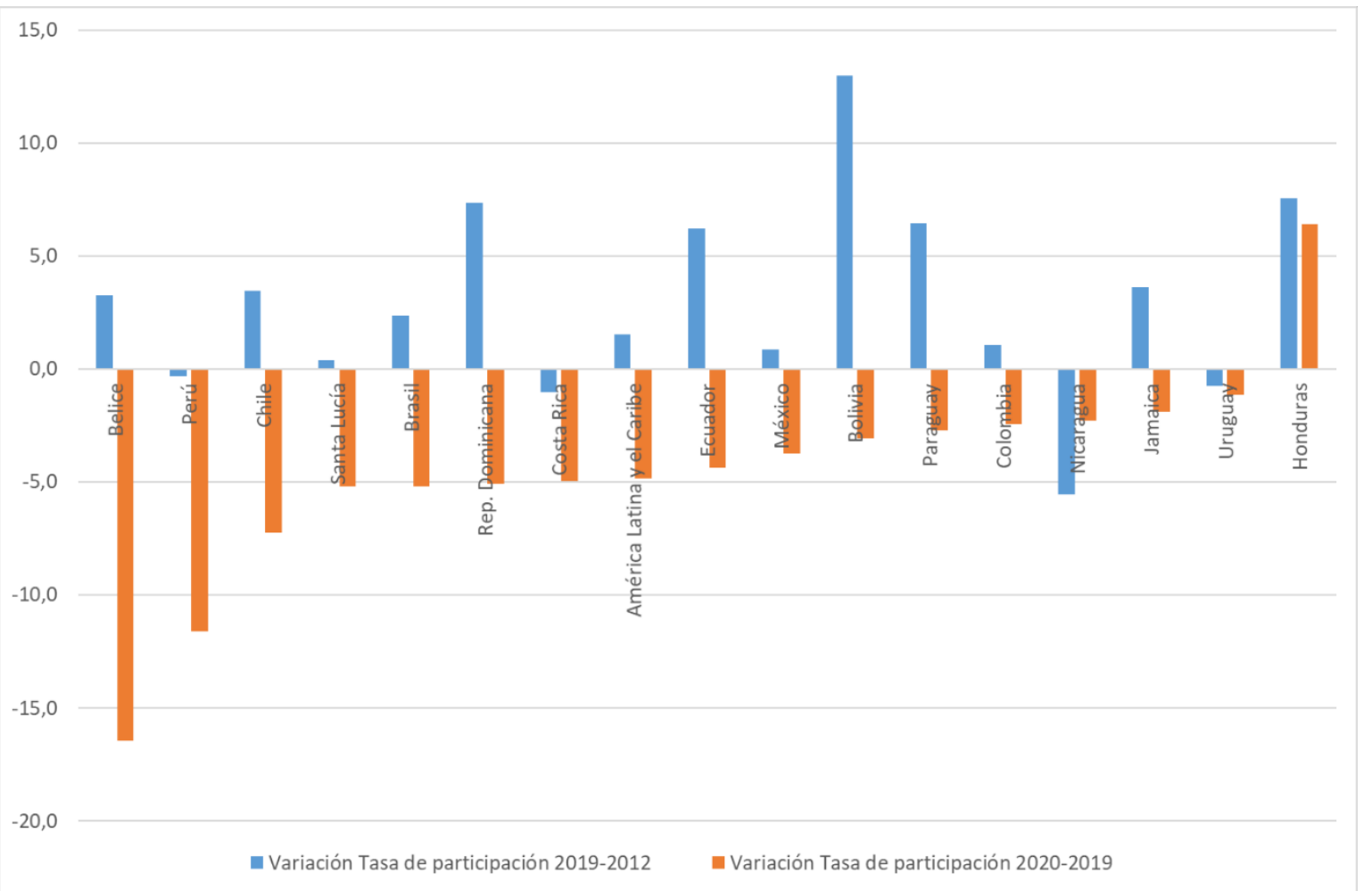

Fuente: Comisión Económica para América Latina y el Caribe (CEPAL) y Organización Internacional del Trabajo (OIT), sobre la base de información oficial de los países

\subsection{Destrucción de empleos en todas las categorías ocupacionales y sectores, aunque más profundas entre los informales y en sectores de servicios}

Los efectos de la crisis sanitaria en el empleo también se aprecian a nivel de categorías ocupacionales, destacándose que la contracción económica afectó con mayor dureza a las categorías ocupacionales de características más informales, sobre todo durante el periodo de confinamiento estricto. Como se aprecia en el Gráfico 7, tanto el empleo asalariado como el empleo por cuenta propia experimentaron contracciones relativamente similares, cerca del $-8 \%$, mientras que categorías ocupacionales como servicio doméstico y el trabajo familiar no remunerado se contrajeron significativamente: $-20,1 \%$ y $11,5 \%$, respectivamente. En particular, la contracción del servicio doméstico significó que en esta categoría de alto nivel de ocupación femenina (cerca del 7\% del empleo total), perdieron su empleo una de cada cinco trabajadoras. A su vez, el cierre de empresas producto de la crisis económica derivada de la pandemia, se tradujo en la pérdida del empleo de uno de cada diez empleadores en la región. No obstante, en términos de cantidad de empleos perdidos, dado que la mayoría de ocupados son asalariados, las pérdidas fueron mayores entre estos. Finalmente, la dinámica observada en 2020 a nivel de categorías ocupacionales pone de relieve otra diferencia de la crisis sanitaria respecto a anteriores episodios de contracción económica regional. Mientras que en crisis pasadas la destrucción de puestos de trabajo se concentró al principio en el empleo asalariado, lo que fue compensado 
parcialmente por el crecimiento del empleo por cuenta propia y de otras categorías de características informales, en el caso de la crisis sanitaria, la destrucción de puestos de trabajo no asalariados fue, en conjunto, proporcionalmente más significativa que la observada a nivel del empleo asalariado. Es decir, el empleo no asalariado no sirvió como amortiguador de la pérdida de empleos asalariados durante la pandemia de la COVID-19.

Gráfico 7.

América Latina y el Caribe (9 países) a: Variación interanual del empleo por categoría de ocupación. 2019 y 2020. (En porcentajes).

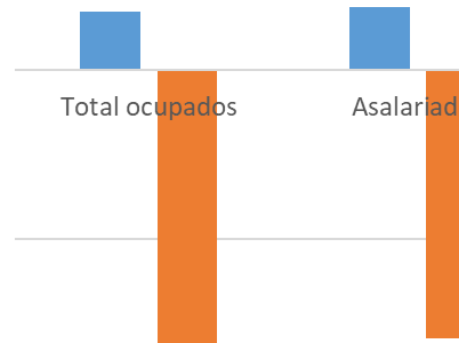

$-10,0$

Fuente: Comisión Económica para América Latina y el Caribe (CEPAL) y Organización Internacional del Trabajo (OIT), sobre la base de información oficial de los países a Promedio ponderado de los siguientes países: Brasil, Chile, Colombia, Costa Rica, Honduras, México, Panamá, Paraguay y República Dominicana. Se incluyen estimaciones basadas en datos parciales.

Como resultado de la contracción del empleo en categorías independientes, hubo mayor destrucción de puestos de trabajo formales que informales, sobre todo al inicio de la pandemia. Para 6 países con información actualizada, se observa que el impacto de la desaceleración económica fue mayor en el empleo informal o de características informales, particularmente en el periodo de confinamiento obligatorio durante el segundo trimestre de 2020 (Gráfico 8). En efecto, en los seis países se observa que tanto el empleo formal como informal se contraen en ese trimestre respecto de los niveles observados a fines de 2019 (índice 100), siendo mucho más profunda la caída del índice de empleo informal. De hecho, la contracción del empleo informal en el segundo trimestre duplica a la experimentada por el empleo 
formal en todos los países. En cambio, desde el tercer trimestre, en que se empezaron a implementar medidas de desconfinamiento, las brechas entre el empleo formal e informal tienden a acortarse en todos los países, llegando incluso a revertirse al final de 2020 en el caso de Paraguay. Esto pone en evidencia que si bien el impacto de las medidas de confinamiento fue mayor en el empleo informal, el proceso de desconfinamiento ha significado una recuperación relativamente más acelerada del empleo de condiciones informales.

\section{Gráfico 8.}

América Latina (países seleccionados). Evolución del nivel de actividad económica, empleo formal y empleo informal. Finales 2019-2020. (en índices, final de 2019=100).

Argentina. IV trim. 2019 - IV trim. 2020

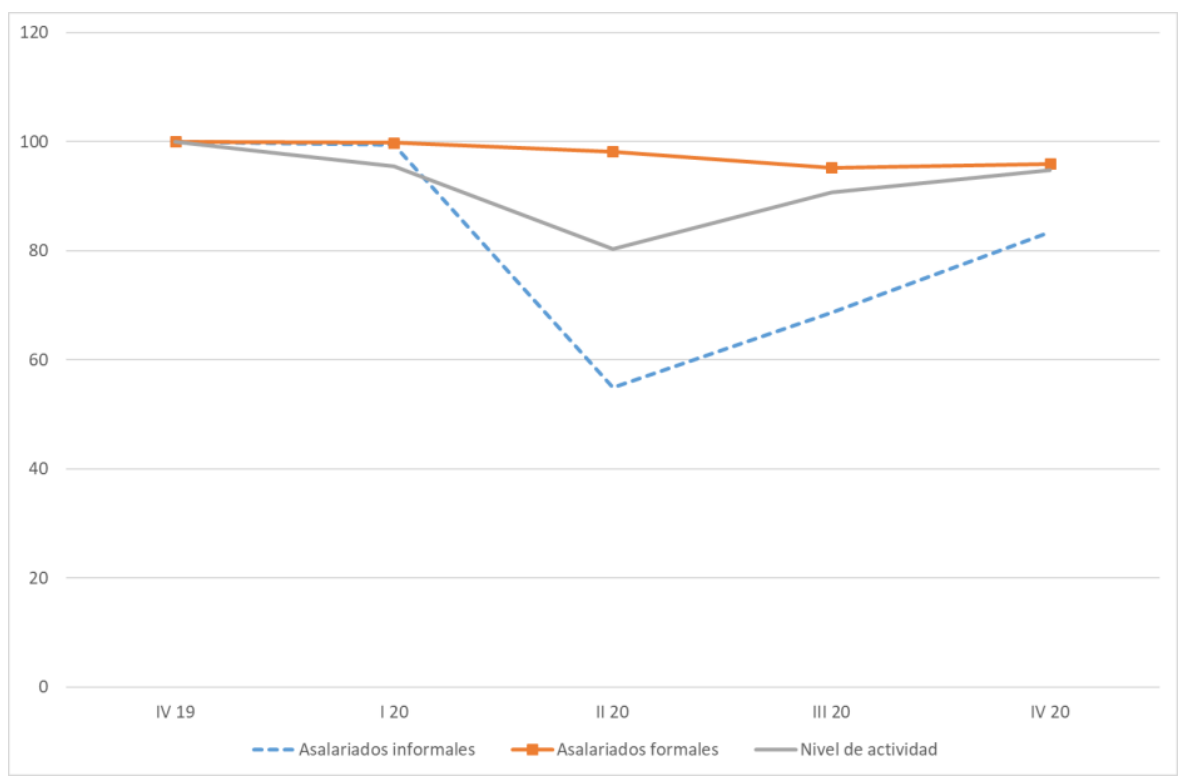

Brasil. Oct-dic 2019 - Oct-dic 2020

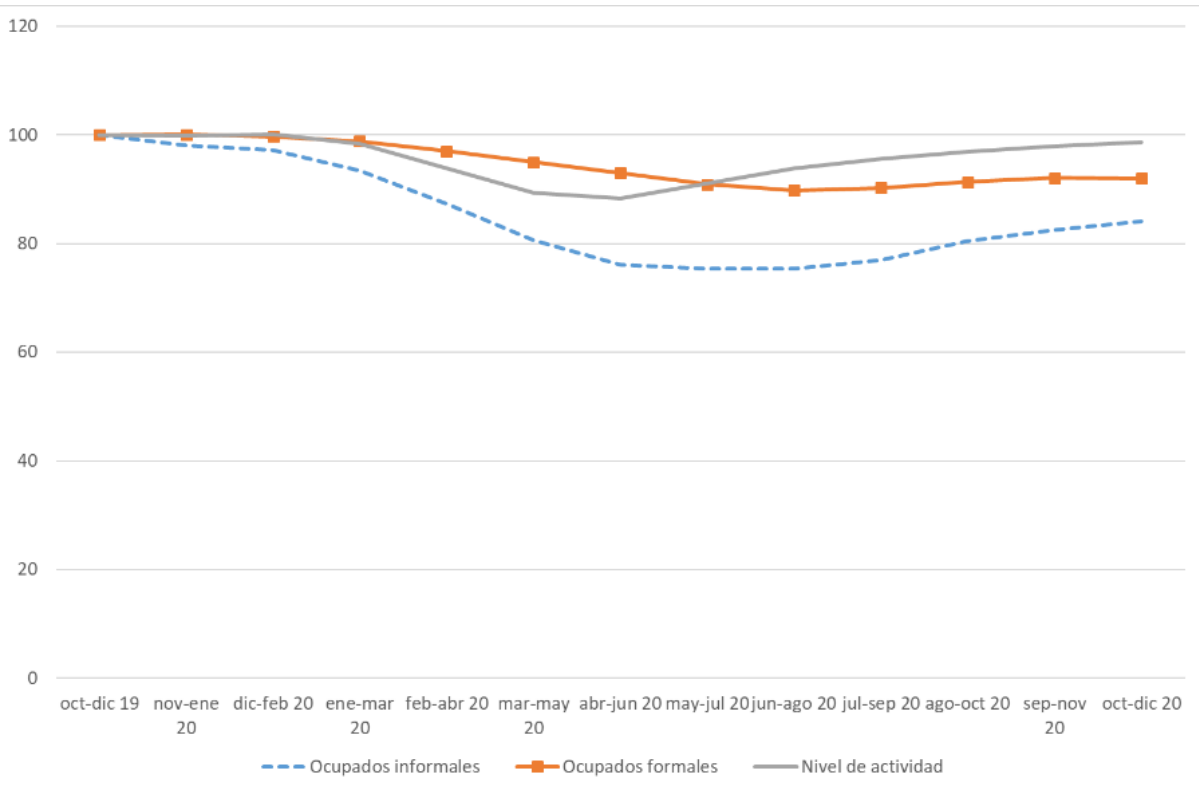


Chile. Oct-dic 2019 - Oct-dic 2020

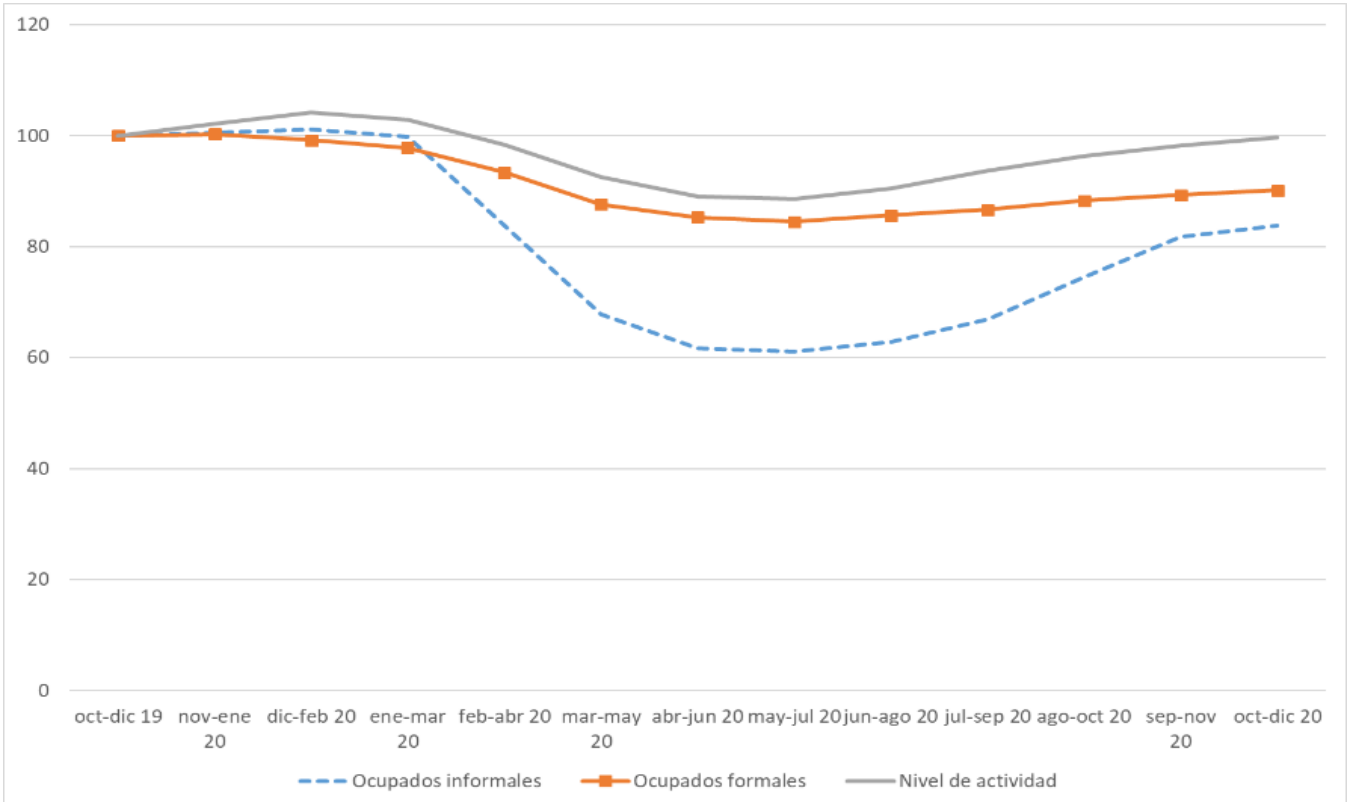

Costa Rica. IV trim. 2019 - IV trim. 2020

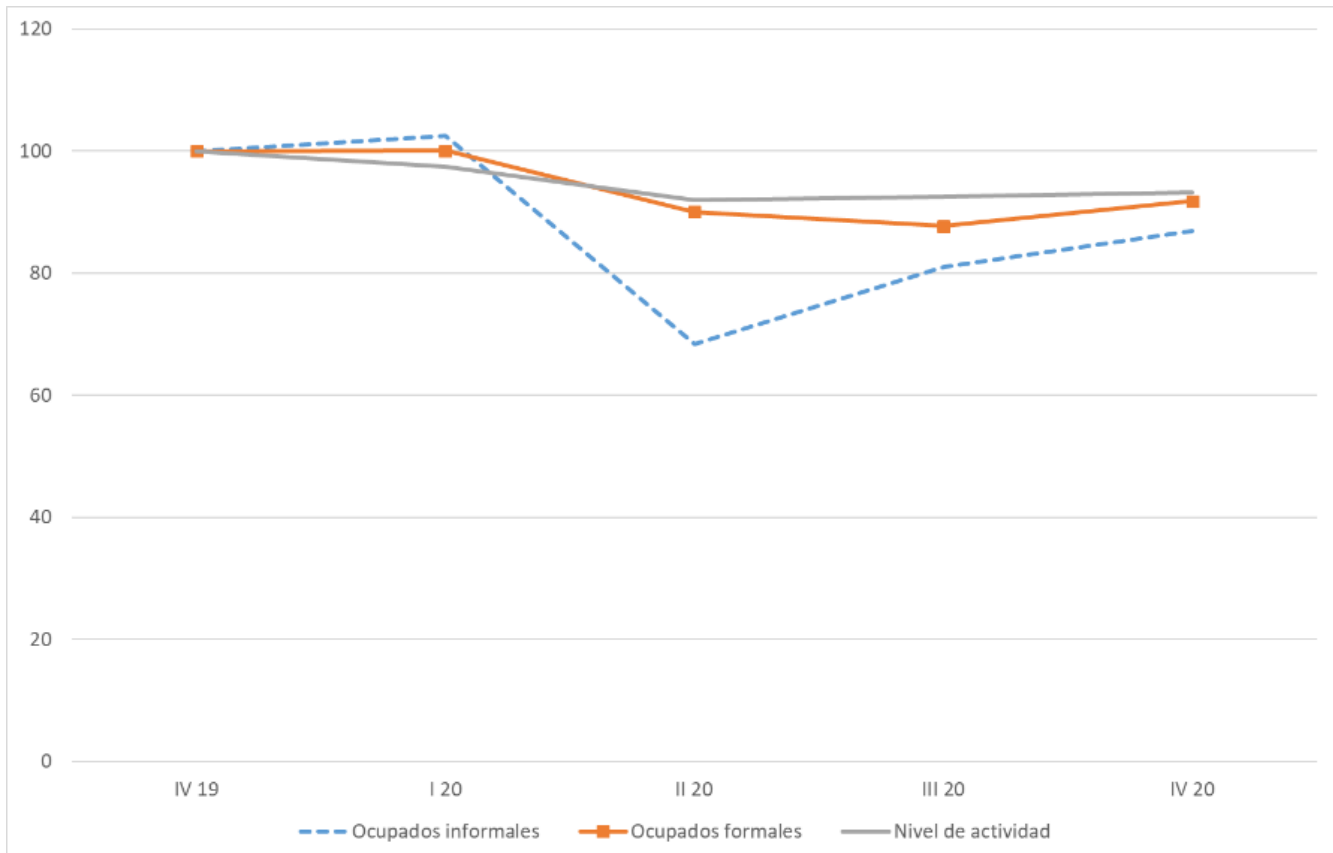


México. Diciembre 2019 - Diciembre 2020

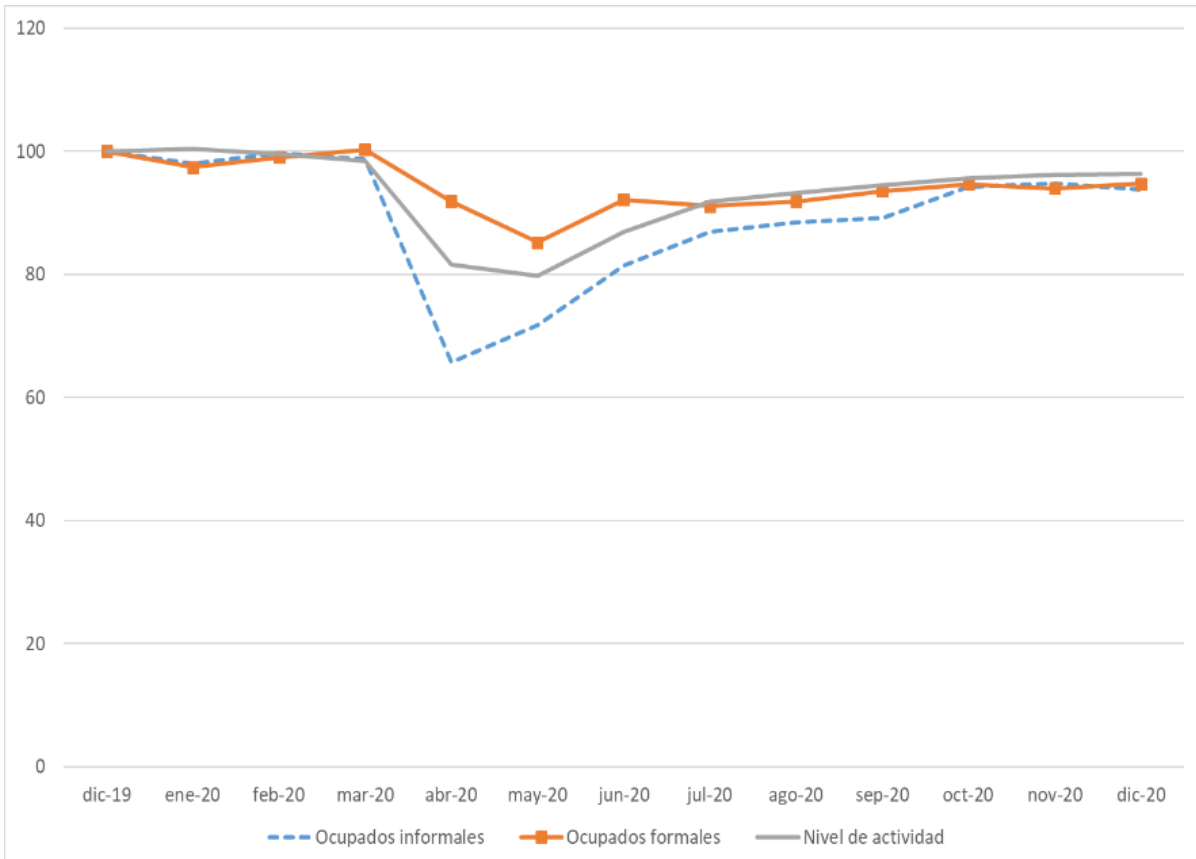

Paraguay. IV trim. 2019 - IV trim. 2020

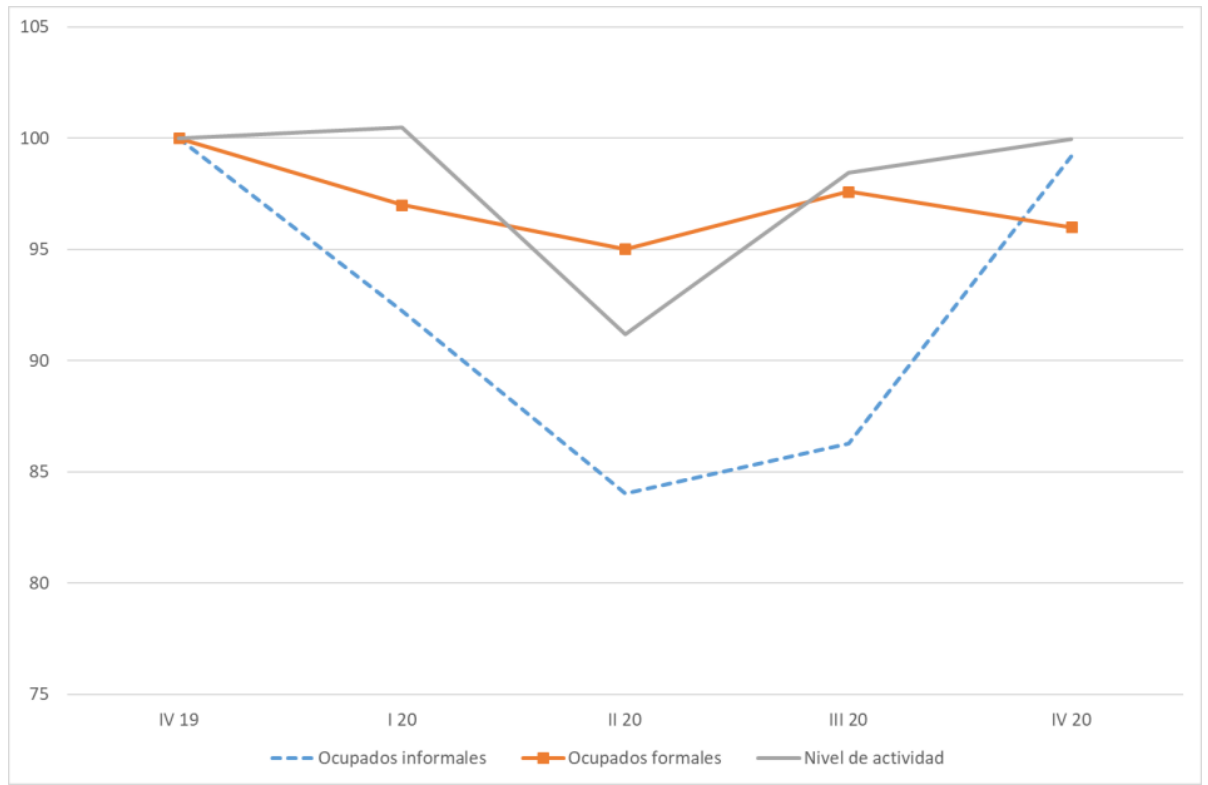

Fuente: OIT (2021), sobre la base de información oficial de los países 
A nivel de ramas de actividad también se aprecian los efectos negativos de la crisis sanitaria, que son más profundos en los sectores económicos más afectados por el descenso de la actividad económica y las medidas de confinamiento y/o limitación del trabajo presencial. Como se aprecia en el Gráfico I.8, la contracción del empleo en 2020 fue mucho más profunda en sectores como Hotelería (19,2\%), Construcción $(11,7 \%)$, Comercio $(10,8 \%)$ y Transporte $(9,2 \%)$, que en conjunto concentran cerca del $40 \%$ del empleo regional. A su vez, la Industria $(-8,6 \%)$ y Otros servicios $(-7,5 \%)$ también registraron contracciones, mientras que en Agricultura (-2,4\%) la pérdida de empleos fue comparativamente menor. $\mathrm{Si}$ bien la dinámica de pérdidas generalizadas de empleo por ramas de actividad es nueva respecto de otras crisis, en que los efectos negativos estuvieron más focalizados a nivel de pocos sectores, la intensidad del impacto en sectores como Hotelería, en que se perdieron cerca de uno de cada cinco empleos, pone en evidencia las dificultades que la transición a la pos-pandemia implicará para la recuperación del empleo en sectores altamente impactados por las medidas de confinamiento y la reducción de la demanda.

\section{Gráfico 9.}

América Latina y el Caribe ( 9 países) a: Variación interanual del empleo por rama de actividad. 2019 y 202 (En porcentajes).

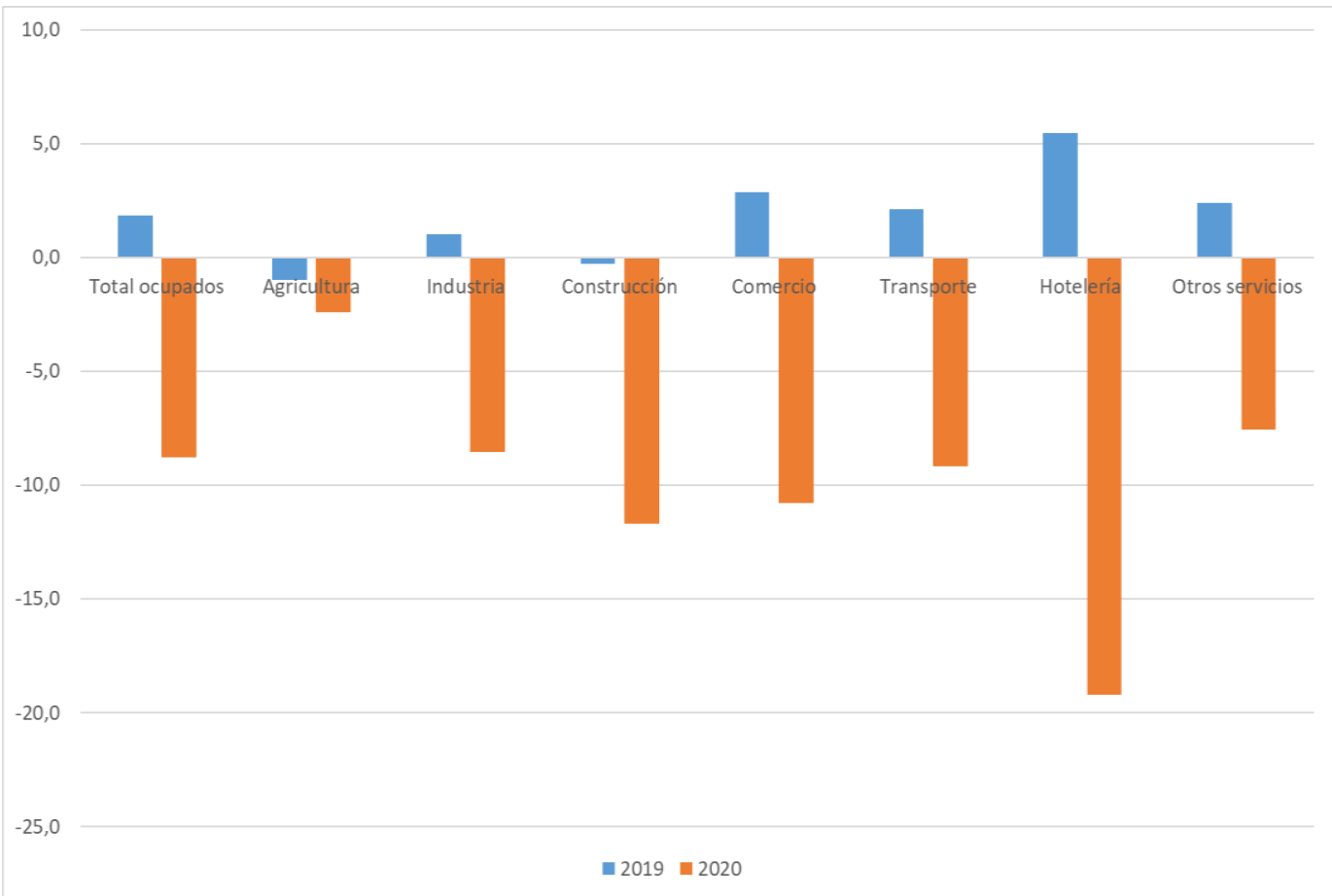

Fuente: Comisión Económica para América Latina y el Caribe (CEPAL) y Organización

Internacional del Trabajo (OIT), sobre la base de información oficial de los países a Promedio ponderado de los siguientes países: Brasil, Chile, Colombia, Costa Rica, Honduras, México, Panamá, Paraguay y República Dominicana. Se incluyen estimaciones basadas en datos parciales. 


\section{Los impactos diferenciadores de la crisis sanitaria: los desafíos pendientes.}

Los datos analizados muestran que el impacto negativo de la crisis sanitaria en los mercados laborales de la región durante 2020 se manifestó en varias facetas, que diferencian a ésta de otras crisis. Por una parte, los efectos negativos en las tasas de participación, ocupación y desocupación afectaron a casi la totalidad de países de la región. Además, la contracción de la participación laboral fue profunda e instantánea, a contramano de los rezagos observados en el pasado, que implicaban una reacción más lenta de la tasa de participación al ciclo económico. La velocidad de ajuste de la tasa de participación contuvo en buena medida lo que en otras circunstancias hubiera implicado un efecto mayor en las tasas de desocupación nacionales y regional. Esta reducción de la participación laboral fue marcada entre las mujeres, revirtiendo la tendencia registrada en las últimas décadas, en que la participación laboral de las mujeres aumentó de manera constante (CEPAL/OIT 2019). Por otra parte, si bien la contracción del empleo fue importante para todas las categorías ocupacionales y ramas de actividad, fue más profunda en las categorías de condiciones más informales. Por ende, la destrucción de empleos informales fue más importante que la contracción del empleo formal, a diferencia de crisis anteriores, en que el empleo informal absorbió una parte de las pérdidas de empleos asalariados y formales.

La destrucción y precarización de empleos, el aumento de la desocupación, la abrupta disminución de la participación laboral, y los efectos en el empleo y participación de las mujeres, entre otros, presentan desafíos de corto y mediano plazo para lo que será la transición paulatina hacia la pos-pandemia. Esa transición dependerá tanto de la efectividad y masificación de las medidas de control de la crisis sanitaria, en particular la vacunación, como de la robustez de la recuperación de la actividad económica en un contexto marcado por la fragilidad del tejido productivo y el sostenimiento de las políticas de transferencias e ingresos para trabajadores, empresas y personas fuera de la fuerza laboral que los gobiernos han implementado desde 2020 (CEPAL, 2020a, 2021; OIT, 2020, Velásquez, 2021).

Dada la profundidad del impacto de la crisis en 2020 y la gravedad de las segundas y terceras olas de la pandemia que se están observando en varios países, con nuevas medidas de confinamiento, es muy probable que desde 2021 los países de la región convivan con tasas de desocupación más altas respecto de los años anteriores. Las tasas de desocupación, que aumentaron en 2020, tenderán a mantenerse elevadas en la medida en que las personas que salieron de la fuerza de trabajo regresen a la misma y se genere un incremento de la oferta laboral que no pueda ser absorbido a la misma velocidad por la demanda. Es muy probable que los empleos formales que se generen, no recuperen los niveles prepandemia en el corto plazo, debido a los problemas que están experimentando muchas empresas, particularmente MIPYMES, para sostener y recuperar su actividad. Ello es particularmente notorio en aquellos sectores como turismo, comercio, transporte y construcción. En consecuencia, instrumentos como los seguros de desempleo, junto con las políticas de capacitación e intermediación laboral, son muy importantes para sostener, por un lado, los ingresos de los desocupados y, por otro, facilitar el retorno al mercado laboral de las personas que se encuentran fuera de la fuerza de trabajo o estén desocupadas. A ello se suma la necesidad de promover la inversión pública y privada de alta intensidad de mano de obra, especialmente en los sectores más afectados en cada país, de manera que la reactivación del tejido productivo en esos sectores acelere la demanda del empleo a nivel sectorial. 
Otro elemento que presenta desafíos para los países de la región tiene que ver con la fuerte destrucción de empleos formales e informales en 2020 y la posibilidad de que la generación de empleos sea mayoritariamente informal. Como se discutió, la contracción económica se tradujo en la destrucción de puestos de trabajo asalariados y del empleo registrado. Por otra parte, la crisis sanitaria, a diferencia de crisis anteriores, impactó con mayor fuerza a los empleos de características informales, especialmente en el periodo de confinamiento. A su vez, se observó que en el periodo de desconfinamiento, los empleos informales han tendido a crecer más que los formales. De mantenerse esta tendencia en 2021, es probable que durante las siguientes "olas" de la pandemia el proceso de recuperación del empleo pueda darse desde la generación de puestos de trabajo de condiciones más informales cuando haya medidas de desconfinamiento o que se profundicen las contracciones del empleo, sobre todo informal, si las medidas de confinamiento se reimplementan. Esto va a representar un gran reto tanto para las políticas como para las instituciones laborales, puesto que los avances de los procesos de formalización del empleo observados en las últimas décadas pueden revertirse en el corto, mediano y largo plazos si la recuperación económica y del tejido productivo no va de la mano con el sostenimiento de las políticas sociolaborales que garantizan pisos de protección social de los y las trabajadoras. Por otra parte, también se presentan desafíos más estructurales, por la necesidad de sostener políticas de ingreso para los trabajadores informales y sus familias durante las siguientes "olas" de la pandemia y en la pos-pandemia.

Un aspecto particularmente desafiante para 2021 y en el periodo pos-pandemia tiene que ver con la recuperación de la dinámica laboral femenina pre-pandemia. Tal como muestra la evidencia (CEPAL-OIT, 2019; OIT, 2019), el incremento constante de la participación femenina regional ha sido el factor clave para explicar el sostenido aumento de la tasa de participación regional en las últimas tres décadas, que ha más que compensado la tendencia a una menor participación laboral de los hombres. La caída de la participación laboral de las mujeres en 2020 significa no solo un fuerte retroceso frente a los avances registrados, también supone desafíos enormes de política para facilitar la reinserción de las mujeres en la fuerza de trabajo. En especial, la caída de la participación durante la pandemia se dio en un contexto marcado por la brecha del uso de tiempo entre hombres y mujeres para las tareas de cuidado (CEPAL, 2020a, 2020b). Por ende, las razones estructurales que marcan el mayor peso en las mujeres del cuidado de personas mayores, niños y enfermos, que explican la brecha, se habrían exacerbado durante la pandemia. Además del desafío de la recuperación del empleo y de las condiciones laborales durante las siguientes "olas" y el periodo pos-pandemia, para facilitar la reincorporación de las mujeres al mercado laboral deben priorizarse las medidas que fortalezcan las políticas e instituciones de los sistemas de cuidados, tanto en términos de educación como de salud. A ello se suman los problemas de reingreso al mercado laboral en un contexto marcado por la pérdida de empleos en categorías feminizadas, como el Servicio Doméstico y las TFNR, de características informales y de bajos ingresos.

\section{REFERENCIAS}

CEPAL (Comisión Económica para América Latina y el Caribe) (2021), Panorama Social de América Latina 2020, Santiago, marzo.

CEPAL (2020a), Observatorio COVID-19 América latina y el Caribe: acciones por país. Versión on-line https://www.cepal.org/es/temas/covid-19. 
CEPAL (2020b), La pandemia del COVID19 profundiza la crisis de los cuidados, Santiago, abril.

CEPAL (2020c), Enfrentar los efectos cada vez mayores del COVID-19 para una reactivación con igualdad: nuevas proyecciones, Santiago, julio.

CEPAL (2019). Panorama Social de América Latina 2018. CEPAL, Santiago de Chile.

CEPAL (2016). Perspectivas económicas de América Latina 2017: juventud, competencias y emprendimiento. CEPAL, Santiago de Chile.

CEPAL (2011). Balance Preliminar de las Economías de América Latina y el Caribe. CEPAL, Santiago.

CEPAL (2010). Balance Preliminar de las Economías de América Latina y el Caribe. CEPAL, Santiago.

CEPAL/OIT (Comisión Económica para América Latina y el Caribe/Organización Internacional del Trabajo) (2018), "Evolución y perspectivas de la participación laboral femenina en América Latina", Coyuntura Laboral en América Latina y el Caribe, No 21 (LC/TS.2019/66), Santiago, mayo.

CEPAL-OIT (2015). Coyuntura laboral en América Latina y el Caribe. Protección social universal en mercados laborales con informalidad. Mayo de 2015, Santiago de Chile.

CEPAL-OIT (2014). Coyuntura laboral en América Latina y el Caribe. Formalización del empleo y distribución de los ingresos laborales. Octubre de 2014, Santiago de Chile.

CEPAL-OIT (2011). Coyuntura laboral en América Latina y el Caribe. Políticas contracíclicas para una recuperación sostenida del empleo. Junio de 2011, Santiago de Chile.

Dargent, E., Lotta, G., Mejía-Guerra, J. A., y Moncada, G. (2018). La economía política de la capacidad estadística en América Latina:i A quién le importa saber?. Banco Interamericano de Desarrollo (BID), Washington.

Escudero, V., Kluve, J., López Mourelo, E., y Pignatti, C. (2019). Active labour market programmes in Latin America and the Caribbean: Evidence from a meta-analysis. The Journal of Development Studies, 55(12), 2644-2661.

Gontero, S., y Zambrano, M. J. (2018). La construcción de sistemas de información sobre el mercado laboral en América Latina. Macroeconomía del desarrollo. CEPAL, Santiago de Chile.

Marinakis, A., y Velásquez, M. (2010). Políticas de empleo: desde la crisis a la recuperación. OIT, Santiago de Chile.

Marinakis, A. (2011). Explaining Latin America's robust recovery from the crisis. Conference on Key Lessons from the Crisis and Way Forward. OIT, Ginebra.

Mourelo, E. L. (2018). Los servicios del mercado de trabajo en América Latina y el Caribe. Ekonomiaz: Revista vasca de economía, (93), 198-217.

Ocampo, J. A. (2011). How Well Has Latin America Fared During the Global Financial Crisis?. Ensayos Económicos, 1(61-62), 733.

OIT (Organización Internacional del Trabajo) (2021), "Transitando la crisis laboral por la pandemia: hacia una recuperación del empleo centrada en las personas", Serie Panorama Laboral en América Latina y el Caribe 2021, Lima, abril. 
OIT (2020), Panorama Laboral en América Latina y el Caribe 2021, Lima, diciembre.

OIT (2019), "Mujeres en el mundo del trabajo. Retos pendientes hacia una efectiva equidad en América Latina y el Caribe", Panorama Laboral Temático, Lima, agosto.

OIT (2018). Panorama Laboral Temático: Presente y futuro de la protección social en América Latina y el Caribe. OIT, Lima.

OIT (2016). Soluciones eficaces: Políticas activas del mercado de trabajo en América Latina y el Caribe. OIT, Ginebra.

OIT (2011). Panorama Laboral 2011. OIT, Lima.

OIT (2010). Panorama Laboral 2010. OIT, Lima.

Salazar-Xirinachs, J. M., y Chacaltana, J. (2018). Políticas de formalización en América Latina: Avances y desafíos. OIT, 2018

Velásquez, M. (2021), La protección social de los trabajadores informales ante los impactos del COVID-19, Santiago, marzo. 